\title{
Sustainable tourism as a method of forming a tolerant society
}

\author{
Svetlana Dryga ${ }^{1, a}$, Maria Aleksandrova ${ }^{1}$, Natalia Goncharova ${ }^{1}$, Olga Sanfirova $^{2}$ \\ ${ }^{1}$ National Research Tomsk Polytechnic University, 30 Lenin Avenue, Tomsk 634034, Russia \\ ${ }^{2}$ Tomsk State Pedagogical University, 60a Kievskaja street, Tomsk 634061, Russia
}

\begin{abstract}
The article concentrates on potential capabilities for the development of sustainable tourism, as well as its role in the formation of tolerant social relations. The authors revealed the profound impact of sustainable and hike tourism on emergence of the phenomenon 'new tourist'. They also offered the description of levels of tolerance and their influence on the sustainable tendencies in modern tourism. There is a growing trend for tourism in modern international community to act as a high-powered regulator of socio-cultural relations and, simultaneously, as the crucial factor of counteraction to that xenophobia. A head-on clash of local and foreign cultures, which is an integral part of the very notion of tourism, is not supposed to assume itself in highly extreme forms, with the air of predominance of any of them, moreover, to be based on national, racial, religious, linguistic or educational differences. To put the idea across more efficiently, the authors resorted to exploiting such useful tools as the analysis and synthesis methodology, as well as that of comparison and prognostics. What is produced in the outcome of this study is revealing and emphasizing the levels of tolerance, characterizing the uneasy interrelationships between the so-called 'new' tourists and local community. The research findings could find practical applications for designing of new tourist products and elaborating of new networks of footpaths for walking tours.
\end{abstract}

\section{Introduction}

The paper presents a review of the scientific literature, describes the trends of tourism development, the issues of forming tolerance in the context of sustainable tourism development. The main conclusions on the issues discussed were formed: the formation of tolerance is one of the priorities of modern society development and could be achieved through the development of sustainable tourism in the context of globalization and rapid development of international tourism, as the inherent properties of both processes. Dynamics of tourism and its sustainable development is directly linked to a socio-economic and cultural development level of a country. Each country has a certain level of living of the population, and the higher it is, the more affordable international travel for the majority of the population is. The growth of international tourism mobility has a positive impact on the level of tolerance of the individual, the more often citizens of the state travel and thus get acquainted with the representatives of other cultures, the higher the General level of tolerance in the country, and the world at large is. The formation of tolerance, in addition, depends on the historical and cultural characteristics of the inhabitants of a country.

This paper is devoted to the correlation of such global phenomena as sustainable tourism and tolerance,

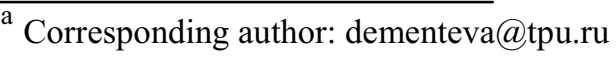

the concept of tolerance was interpreted after R. Forst as "a virtue of justice" or "forced virtue" [1]. The authors analyzed and extended the contemporary research of sustainable tourism in the scope of interdependence between sustainability and mass tourism development [2]. An issue of sustainable tourism development has attracted much attention with the immense growth of mass tourism and the impacts of this growth: negative and positive. This paper represents the first step towards the synthesis of levels of tolerance and Doxey's Irridex model and the creation of a tolerant society through sustainable tourism approach. The sustainable tourism development demands the definite model of gest behavior that integrates a tolerant attitude, adaptation to local culture and responsible consumption [3].

\section{Sustainable tourism in the context of universal problems}

In 1972 Danella and Dennis Meadows from Massachusetts published a report under the title 'Limits of Growth' ("Das Grenzen des Wachstums"), where they investigated the influence of economic growth on the world and its future. By means of computer simulation, they supported their claim that the world will inevitably fail to cope with the alarming rate of the use of natural resources and environmental pollution, generated by the 
current economic growth. Within the scope of systems approach it was suggested that the business system is in urgent need of drastic changes in order to attain a universal equilibrium state [4].

The authors unambiguously determine that the future of our planet is a matter of grave concern due to the growing overpopulation, and this situation is a far cry from sustainability in compliance with limited natural resources available. "World Conversation Strategy", issued in 1980 by International Council for the Discussion of Nature and Natural Resources was one of the first reports, in which it was announced avowedly about the conception of sustainable development. In 1987 International Committee for Environment and Sustainable Development published the official "Report of the World Commission on Environment and Development: Our Common Future", also world-famous as Brundtland's report. The author puts the conception of sustainable development in the forefront defining it as salvation [5]. That report was based on her wellconsidered idea that people had not inherited the Earth from their ancestors, but, instead, they were supposed to pass it on to another generation.

Since 1987 there has been generated the growing worldwide interest for sustainable development. Rio de Janeiro Summit in 1992 and 'Agenda 21' (Agenda for the 21 th century), as well as such natural burning issues as 'global warming' and 'smog', which exerted a profound impact on South East Asia in 1997, proved to be acting as powerful incentives to keeping the process on the boil. At the same time those years saw a massive influx of tourists - the fact, which by no means exerted salutary influence on the local ecology of the host country [6].

The ideas of sustainable development were transferred to many spheres of human activity and were applied with willingness by researchers to tourism sector. It was J. Swarbrooke who in 1999 first emphasized the impact of sustainable tourism on the environment, natural and social resources of the region, behavior of residents of a destination [2]. A lot of progress was done from that time to enrich Tourism Studies with sustainability issues. Among researchers who have made a substantial input into developing and systemizing past and current research on Sustainable Tourism Development are B. Bramwell, B. Lane, C.H. Liu, J. Saarinen, R. Sharpley, D. Weaver, S. Hashemkhani Zolfani et al [7, 8, 9, 10, 11, 12, 13, 14].

B. Bramwell and B. Lane [7] have conducted a research aimed to group the articles making new contributions to theoretical understanding of sustainable tourism:

1) political ecology and sustainable tourism (e.g. S. Cole, S. Stonich, S. Gossling);

2) mobilities and sustainable tourism (e.g. D. Dredge \& T. Jamal);

3) transition pathways for sustainable travel (e.g. A. Williams);

4) behavioural and systems change for sustainable tourist travel (J. Higham, S. Cohen, P. Peeters and S. Gossling).
The second and the forth groups of research are the most relative to the article. They explore "the tensions between mobilities and established sustainable tourism principles that suggest governance should be grounded in local community dialogue and values" [15] and "behavioural change by individual tourists, compared with change in societal systems, for securing more sustainable tourist travel patterns" [16]. The article by K. Kayat (2014) engages with conceptual ideas of Community-based Tourism (CBT) concerning community involvement, empowerment and leadership in sustainable rural tourism [17].

\section{'New tourist' as an active participant in a tolerant society}

Analysis of sustainable tourism presupposes the transition from the study of technological problems to social and philosophical issues.

A philosophy of tolerance in the process of overcoming xenophobia towards "the Other" results from the vital necessity to devise reliable methods of theoretical and practical solution of the problem possibility in principle of peaceful coexistence diverse social communities, social groups and particular individuals in integrated social and cultural environment.

Similar to xenophobia, tolerance comes into existence on the borderline area of any (interpersonal, national, religious, linguistic, ethnic, etc.) communication. Thereby, the problem solving can be logically structured into the following levels of tolerance:

The first level - the attitude towards another person as though he/she was a thing. There is a widespread misunderstanding of cultural values, language, symbolic in the outcome. Zero level of tolerance generates the unprecedented level of xenophobia.

The second level refers to mutual benefit relationship. Tolerant behavior brings benefits (material, social, status). Thereafter, the language, value-sense scale and ritual reality of an alien arouse suspicion, with time turning into curiosity. At this level tolerance and xenophobia partly overlap. Perception of something allogenic happens only when it is not supposed to overstep the limits of total balance of conventional values.

The third level - the attitude to an alien is formed within the bounds of legal system of the dominating stratum. Tolerant attitude to alien is maintained according to the law. Tourism business experience clearly shows a large amount of cases when a profound ignorance of legal standards of behavior by travelers still incur severe penalties on them.

The forth level - the attitude to an alien when you treat him/her as your equal, who knows and observes conventional cultural, linguistic, moral and other norms not under compulsion but voluntarily, as a free personality.

An objective analysis of each of these highlighted levels enabled the authors to elaborate key philosophic 
concepts of overcoming xenophobia from a position of tolerance.

A number of modern researchers, dealing with the issue of tolerant behavior, claim that in a society, where sustainable tourism begins to predominate there is a distinct possibility of gaining favorable impressions during and after the process of travelling.

Having made a close study of contemporary research in gests and hosts relationships, the authors have applied Doxey's Irridex Model and findings of M. Smith and enlarged stages of the residents' response with the description of tolerance levels [3, 6].

The first one - euphoria - is an initial stage, good relations between local and tourists [3]. There is a tolerant behavior and practically lack of xenophobia.

The second stage is characterized by apathy [3]. Transition to this stage depends on rates of progress and indicators of tourism development. Mass tourism leads to the onset of distinctive symptoms of fatigue, displayed by local population as a result of a massive influx of tourists and their often disorderly requirements. What then happens is formalization of these contacts; tourists are considered stereotypically as 'a cash cow'. The level of tolerance reduces, and isolated cases of typical symptoms of xenophobia developed by the locals are becoming commonplace.

The third one is irritation. Local residents start to cast doubt on positive benefits from tourism. The onset of xenophobia as growing phenomena, tolerance is regarded as an isolated phenomenon.

The forth stage - hostility. All the problems of social and personal relationships are put down to the large influx of tourists, who destroy (corrupt) traditional cultural and moral values, as well as the very lifestyle concept of the natives. Xenophobia acts as a dominating factor of the attitude to alien, in this case - towards tourists.

As a result, the authors came to conclusion that the ideal stage for creation a tolerance between destination actors is the first one (euphoria), the next challenge is to develop and safe the tolerance on the forth level $[18,19]$.

The psychological mechanisms of formation of tolerant installations could be formed and developed through the implementation of sustainable development principles in tourism. People travelling to another country come in contact with the local population and are involved into the communication process. The milestone of the communication is a desire to understand an interlocutor (a representative of other culture) and to facilitate the process of communication. Moreover, a tourist must respect the laws, customs and traditions of the host country and adjust his or her behavior in accordance with them. In other words, a tourist shows flexibility in overcoming the stereotypes that helps for a compromise in dialogues with the representatives of different cultures. A tourist could not completely escape from the unfamiliar environment and to live in a complete cultural vacuum while travelling, therefore, he or she is involved in joint activities with the local population to a certain extent; there is a dialogue of cultures, depending on the quality and intensity of communication - the exchange of cultural knowledge, adaptation to traditions. Indirectly, through the excursions and the stories of guides, the tourists learn about local culture and learn to accept the others. The result is an adaptation to the cultural environment. Joint activities with local people bring to a mutual transfer (translation) of knowledge, forms and methods of learning. The more one travels the more skills and experience are obtained. A congruent empathy arising in the process of cultural exchange enables the understanding and the acceptance that makes a person be focused on a self-respect and respect to others, combining self-sufficiency and inner freedom. In the complex process of adaptation a tourist may receive a special state that is called by psychologists as a "culture shock". For the first time this term was used by the anthropologist Kalverom Oberg. The phenomenon is that cultural norms faced by a foreigner abroad are in internal contradiction with the norms of a home country [20].

This condition is accompanied by "inclusion" in a new culture and not always with positive emotions - a surprise or discomfort because of the knowledge gap, as well as a confusion in the value orientations, social and personal identity. The symptoms of culture shock are very diverse: the constant concern about the quality of food, drinking water, the cleanliness of utensils, beddings, a fear of contact with people of another culture, a general anxiety, an irritability, the lack of selfconfidence. The sense of the loss of control over the situation, their own incompetence and failure of expectations could be resulted in the fits of anger, aggressiveness and hostility towards the representatives of the host country that does not contribute to the formation of harmonious interpersonal and intercultural relations.

Thus, an immediately after arrival to another country a tourist is experiencing only positive emotions, meanwhile, as the deeper interaction with other cultures, a "rose colored glasses" wears off and cultural contradictions (culture shock stage) appear that are followed by natural internal adjustment to the new environment (adaptation stage).

Researcher Stephen Rhinesmith outlines Ten Stages of Adjustment to a foreign culture [21]:

1. initial anxiety

2. initial elation

3. initial culture shock

4. superficial adjustment

5. depression-frustration

6. acceptance of host culture

7. return anxiety

8. return elation

9. re-entry shock

10. reintegration

The cultural attractions and historical sites of a destination substantially contribute to the overcoming a "culture shock" by a tourist - a person should often go on excursions and get acquainted with the culture and traditions of the people [21].

Social environment of a home country has a great influence on the development of tolerant attitude. It is so called "prerequisites" of a tourist. The development of 
tourism depends on socio-cultural and economic development of the country.

Tolerance is understood as a positive image of the other ethnic culture with preserving the positive perception of the own culture and the absence of negative relation to it. The practice of tolerance does not imply a complete acceptance of the different worldviews or lifestyles; it is more about to grant others the right to live in accordance with their own worldview. Moreover, it does not mean the toleration of the social injustice or the abandonment of belief or weakening of one's convictions and the imposition of their beliefs to others.

\section{Conclusion}

The conducted analysis has proved the fact that sustainable tourism is able to develop tolerant consciousness in the process of cultural communication between a resident and a visitor. Tourism acts as an effective method of developing of tolerance, as it favours closer communication between different cultures and nations. However, it should be considered that tourism in certain conditions without sustainable approach can provoke xenophobia, along with its negative effects.

\section{Acknowledgment}

This article was prepared with the support of research grants of the Russian Humanitarian Foundation "Social memory space on the Internet as a resource for the formation of collective identity" 15-13-70001.

\section{References}

1. R. Forst, Toleranz: philosophische Grundlagen und gesellschaftliche Praxis einer umstrittenen Tugend, 48 (2000)

2. J. Swarbrooke, Sustainable tourism management, (1999)

3. G.V. Doxey, A causation theory of visitor-resident irritants: Methodology and research inferences. In the impact of tourism sixth annual conference proc of the travel research Association, 195-98 (1975)

4. D. \& D. Meadows, H. Meadows, Die Grenzen des Wachstums: Bericht des Club of Rome zur Lage der Menschheit (1972)

5. G. H Brundtland, Environmental Conservation, 14(04), 291-294 (1987)

6. M. Smith, Issues in cultural tourism studies (2009)

7. B. Bramwell, Annals of Tourism Research, 54, 204218 (2015)

8. B. Bramwell, B. Lane, Journal of Sustainable Tourism, 22(1), 1-8 (2014)

9. B. Bramwell, B. Lane, Journal of Sustainable Tourism, 21(1), 1-4 (2013)

10. J. Liu, Z. Ouyang, H. Miao, Journal of Environmental Management, 91(11), 2254-2262 (2010)

11. J. Saarinen, Annals of Tourism Research, 33, 11211140 (2006)
12. R. Sharpley, Tourism development and the environment: Beyond sustainability? (2009)

13. D. B. Weaver, Tourism Management, 33(5), 10301037 (2012)

14. S. Hashemkhani Zolfani, M. Sedaghat, R. Maknoon, E. K. Zavadskas, Economic Research-Ekonomska Istraživanja, 28(1), 1-30 (2015)

15. D. Dredge, T. Jamal, Journal of Sustainable Tourism, 21(4), 557-579 (2013)

16. J. Higham, S. A. Cohen, P. Peeters, S. Gössling, Journal of Sustainable Tourism, 21(7), 949-967 (2013)

17. K. Kayat, SHS Web of Conferences, 12, 01010 (2014)

18. O. Loiko, Ustoychivoe razvitiye $i$ planirivanie $v$ turizme (Sustainable tourism development and planning) (2013)

19. N. Goncharova, Bulletin of Kemerovo State University, 2/7 (62), 158-163 (2015)

20. O. Kalverom, Practical Anthropology, Vol. 7, 177 - 182 (1960)

21. The Center for Global Education website and "Returning Home" by the Canadian Bureau for International Education, 7 (1984) 